\title{
Research on the Influence of Agricultural Technology Innovation on Farmer's Income
}

\author{
Zhao $\mathrm{Yi}$
}

\author{
School of Management and Economy, North China University of Water Resources and Electric \\ Power, Zhengzhou, Henan China 450046 \\ 394922823@qq.com
}

Keywords: Agricultural technology innovation; Income from farmers; Impact

\begin{abstract}
The impact of agricultural technology innovation on farmers' income is through labor productivity, product optimization, variety diversification, labor transfer and other mechanisms. Based on the data of 2005-2016, this paper makes an empirical analysis on the relationship between agricultural technology innovation and peasant income in China by using the simultaneous equation model. The result shows that agricultural technology innovation does not play its due promotion effect, but restricts and even hinders the increase of farmer's income to some extent.
\end{abstract}

\section{Introduction}

The party's nineteenth report pointed out that the problem of rural peasant farmers is a fundamental issue concerning the national economy and the people's livelihood. Agricultural modernization is the effective way to consolidate the basic status of agriculture and promote the income of farmers from "stable rise" to "stable growth" under the new normal economy. The key of agricultural modernization is to transform the traditional backward agricultural production mode into the modern advanced agricultural production mode, while agricultural technological innovation is an important driving force to accelerate this process. Therefore, how to accelerate agricultural technological innovation, strengthening agricultural technological innovation driving role of farmers' income, thus promoting diversified steady increase farmers' income in our country has become one of the focus of the from all walks of life. From the perspective of China, the research on the impact of agricultural technology innovation on farmers' income is relatively more theoretical and less empirical. It is necessary to make an empirical study on the impact of agricultural technology innovation on farmers' income and provide reliable theoretical basis for promoting agricultural science and technology innovation and farmers' income. Based on this, this paper explores the impact of agricultural technology innovation on farmers' income through empirical analysis.

\section{Theoretical Mechanism Analysis}

Agricultural technology innovation refers to the potential benefits in order to obtain, through the research and development of new technology or the introduction, transmission, transformation, application and so on a series of activities, the combination of production factors will vary or recombination, resulting in a benefit of the sum of all the technical and economic activities ${ }^{[1]}$. Hayami and Ruttan proposed the induction innovation model in the process of agricultural development on the basis of the manufacturers of Hicks and Schmookler_Griliches ${ }^{[2-3]}$. Liu Jianhe (2009) believe that agricultural technological innovation is a process of introducing, digesting, absorbing, imitating, improving and diffusing agricultural technologies and recombining the original agricultural techniques. Is also an advanced material equipment and application means of reasonable and effective configuration resources, through market agricultural new ideas, new technology, and the original factors of production (inputs) into a new long-term appreciation of agronomic and new agricultural products, continuously improve the process of agricultural production, social economic and ecological benefits ${ }^{[4]}$. Liu Jianfei (2012) also believes that agricultural technological innovation is an innovation process that includes three core links of agricultural technology research and development, application and diffusion ${ }^{[5]}$.as shown in FIG. 1, 
agricultural technology innovation is a dynamic process, and the impact on farmers' income may have short-term and long-term effects, which may vary in different periods. The research of Zhou Bo (2011) shows that agricultural technology application has a negative impact on household income in the short term, but in the overall trend, the impact on household income growth is positive $^{[6]}$.

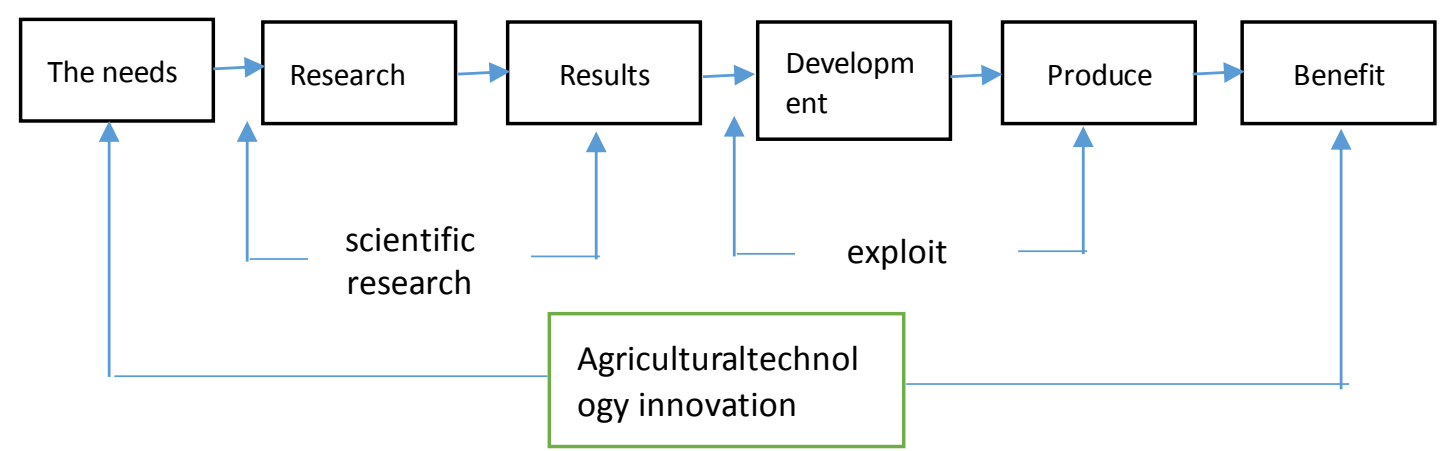

FIG. 1 flowchart of agricultural technology innovation.

\section{Measurement Model Construction and Data Description}

Econometric model to build

The theory and measurement method of the contribution rate of scientific and technological progress is a problem that is still being explored in the academic field, and the calculation method is more complicated. In this paper, the general form of the cob-douglas production function model used in Sun Qiuxia (2010) is used as ${ }^{[7]}$ :

$$
y_{t}=A m_{t}^{\alpha} l_{t}^{\beta} s_{t}^{\gamma} e_{t}^{\delta}
$$

Where, $\mathrm{y}$ is the total output value of agriculture, $\mathrm{A}$ is the constant term, $\mathrm{m}, 1, \mathrm{~s}$ are the material cost, labor force and cultivated area, $t$ is the time variable. It can be proved that $\alpha$ is the elastic coefficient of material cost; $\beta$ is the elasticity coefficient of labor force; $\gamma$ is the elastic coefficient of cultivated area; $\delta$ is the rate of agricultural science and technology progress. That is, the increase in agricultural output due to scientific and technological progress.

Generally, the contribution rate of agricultural science and technology progress is the contribution share of agricultural scientific and technological progress to the growth rate of agricultural gross output. The formula is:

Agricultural science and technology progress contribution rate $=$ agricultural science and technology progress rate/agricultural output growth rate.

Among them, the rate of scientific and technological progress refers to the total output growth rate due to the progress of science and technology. However, the increase of agricultural output value comes from two aspects: the increase of input of agricultural production factors and the improvement of input-output ratio of agricultural science and technology.

Based on the foregoing analysis and the establishment of the research hypothesis, the following model is established according to Wang Aimin's (2014) ideology ${ }^{[8]}$ :

$\ln$ Revenue $=\alpha_{1}+\beta_{11} \ln$ productivity $+\beta_{12}$ quality $+\beta_{13} \operatorname{lndiversify}+\beta_{14}$ transfer +

$$
\beta_{15} \ln g d p+\mu_{1}
$$

$\ln$ productivity $=\alpha_{2}+\beta_{21}$ tech_innova $+\beta_{22} \ln$ machinery $+\beta_{23} \ln$ fertilization + $\beta_{24}$ irrigation $+\mu_{2}$

$$
\begin{aligned}
& \text { quality }=\alpha_{3}+\beta_{31} \text { tech_innova }+\beta_{32} \text { infrastructure }+\beta_{33} \text { marketization }+\mu_{3} \\
& \text { lndiversify }=\alpha_{4}+\beta_{41} \text { tech_innova }+\beta_{42} \text { education }+\beta_{43} \text { urbanization }+\mu_{4} \\
& \text { transfer }=\alpha_{5}+\beta_{51} \text { tech_innova }+\beta_{52} \text { marketization }+\beta_{53} \text { income_gap }+\mu_{5}
\end{aligned}
$$

Equation (1) represents the income equation, the selection of productivity, the productivity, quality optimization (quality), species diversity, diversify and labor transfer (transfer) as explained 
variable, with analysis of agricultural technology innovation overall impact on the farmers' income (Revenue). In addition, the rural economic level (GDP) of the control variable was also increased, which was reflected by the gross output value of the per capita agriculture, forestry, animal husbandry and fishery.

Equation (2) is the agricultural productivity equation, and the explanatory variable is the agricultural technology innovation (tech_innova), which is usually reflected by the contribution rate of agricultural science and technology. The mechanical power (machinery), the amount of fertilizer applied per mu and the effective irrigation ratio (irrigation) were selected as the control variables.

Equation (3) is the product quality optimization equation, and the explanatory variable is agricultural technology innovation. The control variable is the infrastructure (frastructure) and the marketization degree (marketization), which is reflected in the proportion of total output value of rural fixed assets investment and non-state-owned industrial enterprises respectively.

Equation (4) represents the diversity equation of the species, and the explanatory variable is agricultural technology innovation. The control variables are farmers' education and urbanization, respectively represented by education years and proportion of urban population.

Equation (5) is the labor transfer equation, and the explanatory variable is agricultural technology innovation. The control variables are marketization and urban-rural income gap (income_gap), respectively. The proportion of total output value of non-state-owned industrial enterprises and urban and rural per capita income ratio are respectively represented.

2.Data description

The data used in this paper are mainly from China rural statistical yearbook, China rural household survey yearbook, China intellectual property yearbook and China statistical yearbook. Due to the lack of continuous years of agricultural science and technology progress contribution rate data, referring to Sun Qiuxia (2010), using the solow residual method to calculate the contribution rate of agricultural science and technology progress. The total value of agricultural output is expressed by the total output value of agriculture, forestry and animal husbandry; The input of agricultural labor force refers to the actual amount of labor input in agricultural production, which is reflected by the number of employees in the first industry. Land input should include the land input of agriculture, forestry and animal husbandry and fishery, and the planting area of crops is approximately replaced. Degree with the fixed number of year of the education of rural labor force culture, according to the rural labor in proportion to the level of education at all levels to convert, which can't read or read little, elementary school, junior high school, high school, technical secondary school, college or above in 1 year, 6, 9, 12 years, 13 years, 16 years; The fixed assets investment of rural households is reflected by the primary fixed assets at the end of the year.

\section{Measurement Result Analysis}

Simultaneous equations of the 3 SLS estimate results are shown in FIG.2: equation 1, the labor transfer the impact on the farmers' income to $1 \%$ significance level, specific as follows: labor transfer $1 \%$, farmers' income decreased by $3.47 \%$, in contrast to the previous expectations, crop variety has significantly positive effects on farmers' income, the examination and approval of new varieties increased by $1 \%$, a $0.35 \%$ increase in farmers' income. In addition, the rural economic level has a significant impact on farmers' income, and the elasticity of rural income to rural economic level is 6.65 .

In equation 2, agricultural technological innovation has a positive impact on quality optimization, but it is not significant. The contribution rate of agricultural scientific and technological progress was increased by one percentage point, and the quality optimization rate increased by 0.00024 percentage points. The degree of infrastructure and marketization has negative influence on quality optimization, but it is not significant.

In equation 3, the impact of agricultural technology innovation on productivity is positive, but it is not significant. When the contribution rate of agricultural science and technology is increased by one percentage point, agricultural productivity increases by 0.0074 percent. The effect of mechanical power on productivity is positively correlated. The amount of fertilizer application has a 
significant negative effect on productivity, and the effective irrigation ratio has a significant positive effect on productivity.

Three-stage least-squares regression

\begin{tabular}{lrrrrrr}
\hline Equation & Obs & Parms & RMSE & "R-sq" & chi2 & P \\
\hline Inrevenue & 12 & 5 & .0360118 & 0.9929 & 2736.74 & 0.0000 \\
quality & 12 & 3 & .0004165 & 0.2932 & 5.87 & 0.1179 \\
lnproducti y & 12 & 4 & .0115523 & 0.9597 & 290.78 & 0.0000 \\
Indiversify & 12 & 3 & .0701055 & 0.9294 & 198.51 & 0.0000 \\
transfer & 12 & 3 & .011175 & 0.1637 & 2.06 & 0.5599
\end{tabular}

\begin{tabular}{|c|c|c|c|c|c|c|}
\hline & Coef. & Std. Err. & $\mathrm{z}$ & $\mathrm{P}>|\mathrm{z}|$ & [95\% Conf. & Interval] \\
\hline \multicolumn{7}{|l|}{ Inrevenue } \\
\hline Inproductivity & .984898 & 1.243502 & 0.79 & 0.428 & -1.452321 & 3.422117 \\
\hline quality & -10.07238 & 28.4471 & -0.35 & 0.723 & -65.82766 & 45.6829 \\
\hline lndiversify & .3496512 & .1374103 & 2.54 & 0.011 & .080332 & .6189704 \\
\hline transfer & -3.469141 & .9379596 & -3.70 & 0.000 & -5.307508 & -1.630774 \\
\hline lngdp & .5609837 & .1398849 & 4.01 & 0.000 & .2868142 & .8351531 \\
\hline -cons $^{\text {con }}$ & 6.649644 & 1.742575 & 3.82 & 0.000 & 3.234259 & 10.06503 \\
\hline \multicolumn{7}{|l|}{ quality } \\
\hline tech_innova & .0002437 & .0001788 & 1.36 & 0.173 & -.0001068 & .0005942 \\
\hline Infertilization & -.0028867 & .004334 & -0.67 & 0.505 & -.0113812 & .0056078 \\
\hline marketization & .0077951 & .0052833 & 1.48 & 0.140 & -.0025599 & .0181501 \\
\hline$-^{\operatorname{cons}}$ & -.0047886 & .017944 & -0.27 & 0.790 & -.0399582 & .0303809 \\
\hline \multicolumn{7}{|l|}{ Inproductivity } \\
\hline tech_innova & .0074233 & .0053574 & 1.39 & 0.166 & -.0030771 & .0179237 \\
\hline Inmachinery & .3281566 & .1109155 & 2.96 & 0.003 & .1107663 & .5455469 \\
\hline Infertilization & -.6297694 & .3813552 & -1.65 & 0.099 & -1.377212 & .117673 \\
\hline irrigation & 3.615504 & .6871721 & 5.26 & 0.000 & 2.268672 & 4.962337 \\
\hline _cons & -3.979669 & 1.432902 & -2.78 & 0.005 & -6.788106 & -1.171232 \\
\hline \multicolumn{7}{|l|}{ Indiversify } \\
\hline tech_innova & -.0434928 & .0301222 & -1.44 & 0.149 & -.1025313 & .0155456 \\
\hline education & -1.156169 & .300379 & -3.85 & 0.000 & -1.744901 & -.5674373 \\
\hline urbanization & .0919897 & .0102091 & 9.01 & 0.000 & .0719801 & .1119992 \\
\hline _cons & 12.13735 & 2.060754 & 5.89 & 0.000 & 8.098348 & 16.17635 \\
\hline \multicolumn{7}{|l|}{ transfer } \\
\hline tech_innova & .0009652 & .0046587 & 0.21 & 0.836 & -.0081656 & .010096 \\
\hline marketization & -.1408177 & .0992307 & -1.42 & 0.156 & -.3353062 & .0536708 \\
\hline income_gap & -.0133132 & .0201314 & -0.66 & 0.508 & -.0527699 & .0261436 \\
\hline _cons & .1835023 & .1198698 & 1.53 & 0.126 & -.0514382 & .4184429 \\
\hline
\end{tabular}

Fig. 2 results of 3SLS estimation of simultaneous equations

In equation 4, agricultural science and technology innovation has negative influence on variety 
diversification, but it is not significant. The contribution rate of agricultural scientific and technological progress was increased by one percent, and the number of new crop varieties decreased by 0.043 percent. The influence of urbanization degree on variety diversification is positively correlated, but the influence of farmers' culture degree is significantly negative.

In equation 5, agricultural science and technology innovation has positive influence on labor transfer, but it is not significant. The contribution rate of agricultural scientific and technological progress was increased by one percentage point and labor transfer by 0.001 percentage point. The effect of marketization degree on labor transfer is not significant. The urban-rural income gap has no significant impact on labor transfer.

\section{Conclusions and Recommendations}

The results of this study show that the effect of agricultural technology innovation on farmers' income is not significant through productivity, product optimization and product diversification. The result shows that agricultural technology innovation does not play its due promotion effect, but restricts and even hinders the increase of farmer's income to some extent. The main influencing factors are shown in the following aspects:

1. Insufficient effective supply of agricultural technology. In 2016, our country agricultural technological progress contribution rate from $34 \%$ in 2015 to $34 \%, 70 \% \sim 80 \%$ compared with that of developed countries [18] the agricultural science and technology progress contribution rate, there is still a large gap existing in our country agricultural technology research and development level and the reality doesn't fit the need.

2. The application transformation channels of agricultural technology achievements are not free. The application rate of agricultural technology achievements in China is less than $30 \%$, which is less than $10 \%$ in scale and industrialization, and the application conversion rate is very low.

3. Farmers have insufficient demand for agricultural technical achievements. The main users of agricultural technological achievements are the farmers, whether the farmers adopt the agricultural technology will directly determine the utility of the agricultural technological achievements, and thus the contribution of the agricultural technological achievements to the increase of farmers. However, due to the small scale of farmers' agricultural production, low scientific and cultural quality of farmers and low comparative income of agricultural production, farmers' demand for agricultural technological achievements is relatively inadequate.

In view of the above problems, in order to effectively play the role of agricultural technology innovation in promoting the income growth of farmers, this paper proposes the following Suggestions:

1. Establish and improve the effective supply mechanism of agricultural technology. We will encourage agricultural research institutions, agricultural enterprises and institutions of higher learning to cooperate, form an alliance of agricultural science and technology innovation, and enhance the capacity for collaborative innovation.

2. Improve the application transformation efficiency of agricultural technological innovation. For extension functions the most key link is the last link of grassroots setups for popularizing agricultural science and technology, there has been fundamentally solved the loosely organized, bull management, mechanism not to live, low efficiency and so on.

3. Vigorously cultivate farmers' internal demand for agricultural technological innovation achievements. Strengthen the supporting system construction of land circulation, eliminate the institutional barriers which land management rights, the rapid advance of agricultural scale operation, and the mass demand for agricultural technology achievements.

4. Promote the construction of agricultural technology market and agricultural technology intermediary institutions. We will foster a new type of agricultural technology socialization service organization, and strengthen the support of intermediary organizations such as agricultural technical information service, technology assessment, intellectual property transaction, and permanent technology market.

5 , promote education training for farmers, improve farmers' scientific and cultural quality and 
agricultural production skills, in order to ensure efficient use of agricultural technology achievements can effectively, to improve the agricultural comparative benefits.

\section{Reference}

[1] Fu Xinhong, Ma Wenbin, Yang Jinxiu. Discussion on the connotation and characteristics of agricultural technological innovation [J]. Journal of mountain agricultural biology, 2003, 22(4):332-335.

[2]Dixit A K, Stiglitz J E. Monopolistic Competition and Optimum Product Diversity[J]. American Economic Review, 1977, 67(3):297-308.

[3] Mcerlean S, Wu Z. Regional agricultural labour productivity convergence in China[J]. Food Policy, 2003, 28(3):237-252.

[4] Liu Jianhe and Zhu Yanxia, Wang Deying. Research on the dynamic effect of land use right transfer on agricultural technological innovation $[\mathrm{J}]$. Science and technology and economy, 2009, 22(2):34-37.

[5] Liu Jianfei. Research on agricultural technology innovation process [D]. Southwest university, 2012.

[6] Zhou Bo, Yu Leng. The impact of agricultural technology application on household income -- a case study of farmers in Jiangxi province [J]. Rural economics of China, 2011(1):49-57.

[7] Sun Qiuxia, Yang Yanyan, Gao Qisheng. Measurement of contribution rate of agricultural science and technology in China [J]. Statistics and decision, 2010(22):148-149.

[8] Wang Aimin, Li Zilian. Research on the influence mechanism of agricultural technology progress on farmers' income [J]. Economic and economic development, 2014, 31(4):31-36. 